\title{
Regular Microstructured Elements for Intensification of Gas-Liquid Contacting Made by Selective Laser Melting
}

\author{
Fabian Grinschek, ${ }^{* \dagger}$ Dongxu Xie, ${ }^{\dagger}$ Michael Klumpp, ${ }^{\dagger, \ddagger \odot}$ Manfred Kraut, $^{\dagger}$ Edgar Hansjosten, ${ }^{\dagger}$ \\ and Roland Dittmeyer*, $*,+0$
}

${ }^{\dagger}$ Institute for Micro Process Engineering (IMVT) and Institute of Catalysis Research and Technology (IKFT), Karlsruhe Institute of Technology (KIT), Eggenstein-Leopoldshafen, Germany

\begin{abstract}
Additive manufacturing (AM) as a novel technique for generating complex geometries is attracting interest in $\mathrm{R} \& \mathrm{D}$. Besides the vast opportunities in rapid prototyping and manufacturing, especially in the chemical industry, the extended possibilities of producing devices highly adapted to specific tasks are opening new avenues for process intensification and miniaturization. In this work 3D-structured components for fluidic devices manufactured by selective laser melting are presented. Fluid guiding elements (FGE) structured with precisely defined fluid passages in the submillimeter range for absorption processes were additively manufactured. The elements were characterized and evaluated for $\mathrm{CO}_{2}$ absorption in water and $\mathrm{NaOH}$ solution. In general, the FGE structures show enhanced gas-liquid mass transfer in $\mathrm{CO}_{2}$ absorption. The absorption coefficient $k_{1}$ for $\mathrm{CO}_{2}$ in water is in the same range as reported for microstructured falling film devices. This example demonstrates the opportunity of using AM to produce innovative fluidic devices.

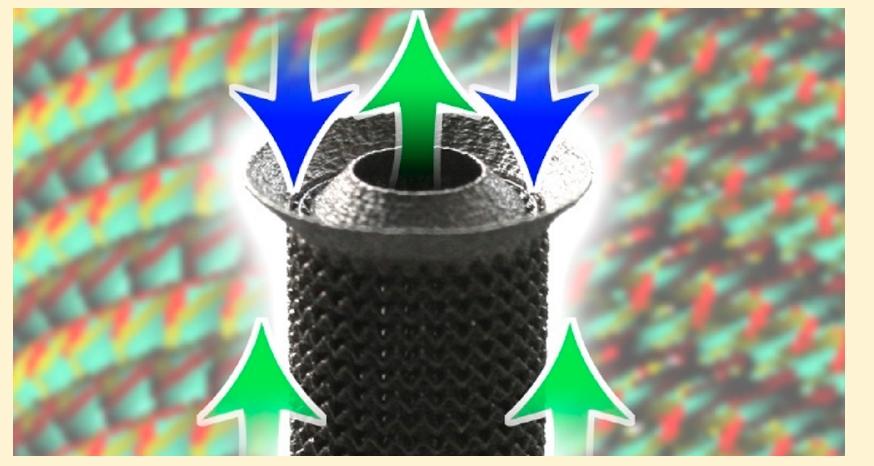

\section{INTRODUCTION}

Additive manufacturing (AM) is increasing the possibilities of manufacturing dramatically. Complex objects can now be produced in just a few hours to days depending on their design, the size, and the used technology. Therefore, R\&D in the field of microprocess technology also aims at exploiting these advantages. ${ }^{1}$ Using conventional methods, like milling, the freedom of design is usually restricted to two dimensions with reasonable effort. For example, channels of a sinusoidal path or flow obstacles in the form of round and rectangular pillars, aligned or unaligned, have been used to generate a secondary flow. ${ }^{2}$ However, using 3D-printing it becomes possible to produce even complex 3D-structures determined by the desired flow field. Since the geometry of a device is not determined strongly by manufacturing boundary conditions, the optimum solution of the process or its flow properties can be derived and the device manufactured to ensure these conditions. The device can now be seen as a geometric solution for the flow problem rather than vice versa. With this new approach of manufacturing, novel, more efficient, more compact, and highly integrated fluidic devices especially in the field of microprocess engineering become feasible.

In recent years a steadily increasing number of scientific publications have been addressing different concepts of AM and emerging applications of the AM itself as well as the novel components produced. For example, in the field of heat transfer fractal ${ }^{3}$ and topology-optimized ${ }^{4,5}$ structures have been proposed. In addition to heat transfer, the advantages of $3 \mathrm{D}$ - printing have also been investigated in other areas of process engineering. For instance, applications in heterogeneous catalysis ${ }^{6}$ were proposed: 3D-printed open porous metallic components such as periodic open cellular structures (“3Dprinted regular foams") were discussed as supporting structures for catalysts which enable excellent heat transfer due to the metallic matrix, while allowing an improved flow distribution and low pressure drop. ${ }^{7-9}$ Porous 3D-printed structures were also discussed as promising filter media. ${ }^{10}$ In the field of separation science, among other concepts, ${ }^{11}$ printed optimized column packings ${ }^{12,13}$ or even whole columns ${ }^{14}$ for rectification and absorption processes are proposed. For example, Fee et al. printed regular structured porous media columns out of acrylonitrile-butadiene-styrene with channel dimensions in the range of 100 to $150 \mu \mathrm{m}$ by stereolithography. ${ }^{15}$

For applications at high temperature and/or under the influence of solvents, additively manufactured metal ${ }^{16-20}$ and ceramic $^{18,21}$ parts are preferred for fluidic devices for use in chemical processes.

Special Issue: Characterization and Applications of Fluidic Devices without Moving Parts

Received: August 21, 2019

Revised: November 4, 2019

Accepted: November 7, 2019

Published: November 7, 2019 
In this work a novel approach to components for fluidic devices manufactured by selective laser melting is presented. These components have been called fluid guiding elements (FGEs). As recently published, when applied as inserts in a tube, thin-walled FGEs divide the flow into specified partial flows and guide them back and forth to the tube wall. ${ }^{22}$ This tailored guidance increases the average effective temperature difference between the wall and the boundary layer, enhancing heat transfer. The design of the FGE is optimized for the production via the SLM process leading to low wall thicknesses and small solid volume of the elements. This provides several advantages: first, the additional pressure drop caused by the FGE insert is very low, and second, the small solid volume allows short producing (printing) times. From an economic point of view this factor is critical, as the manufacturing costs per unit of (metal) volume for AM processes are still much higher compared to conventional fabrication methods. In this work, we present the adaption and application of FGE as a double-sided cylindrical microstructured absorption device. The idea of using a microstructured element to increase mass transfer in gas/liquid contacting is not new: among others, $\mathrm{Hecht}^{23}$ showed an increase in mass transfer of a microstructured device in comparison to a conventional falling film reactor. The formation of rivulets is especially reduced by the microstructuring. Recently, Chen et al. ${ }^{24}$ showed that mixing structures in a falling film reactor gives rise to increased mass transfer due to induced mixing. The microstructured devices in both studies were manufactured using conventional techniques. This contribution aims at showing that a combination of intelligently designed structures and advanced printing techniques yield new opportunities for creating devices showing potential to increase efficiency and thus contributing to process intensification.

\section{DESIGN STRATEGIES}

2.1. Selective Laser Melting. For manufacturing of the fluid guiding elements (FGE) discussed in this work, selective laser melting (SLM) was used. For details on the working principle of SLM as well as of other AM techniques we refer to the comprehensive review articles by Gao and Leu, ${ }^{18}$ Körner $^{17}$ and Santos et al. ${ }^{20}$ In brief, the SLM technique is based on the selective melting of metallic powder using a laser beam. The beam path is predetermined by the printing parameters defined following a sliced three-dimensional model of the structure to be printed. After printing the first layer, the building platform is lowered by a certain layer thickness, and fresh metal powder is provided via a blade before starting the printing of the subsequent layer. Thus, layer by layer, the laser beam prints the structure.

2.2. Design of the Fluid Guiding Elements for Intensified Absorption Processes. The basic design of the used FGE is shown in Figure 1. In a previous paper, ${ }^{22}$ the basic ideas behind the design and printing strategy for FGE for heat exchangers are described in detail. In this work, the adaption of these FGE to mass transfer applications is presented.

The design of the FGE is based on unit cells or fluid guiding units (FGUs) consisting of B-Spline surfaces defining the midline of the FGE wall which is multiplied and transformed into the desired shape (compare also Figure 2).

Here, a FGU is defined as the structural element, which connects the two sides by inverting the plane of flow. The basic idea of FGE to increase the heat transfer by guiding the flow in

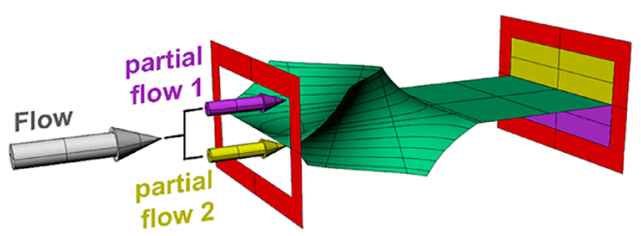

Figure 1. Principle of fluid guiding unit (FGU) of the FGE as described in Hansjosten et al. ${ }^{22}$ By the FGU the flow is divided into two partial flows (purple and yellow colors) which are inverted after flowing through the FGU. Adapted with permission from Hansjosten et al. ${ }^{22}$. Copyright 2018 Elsevier.

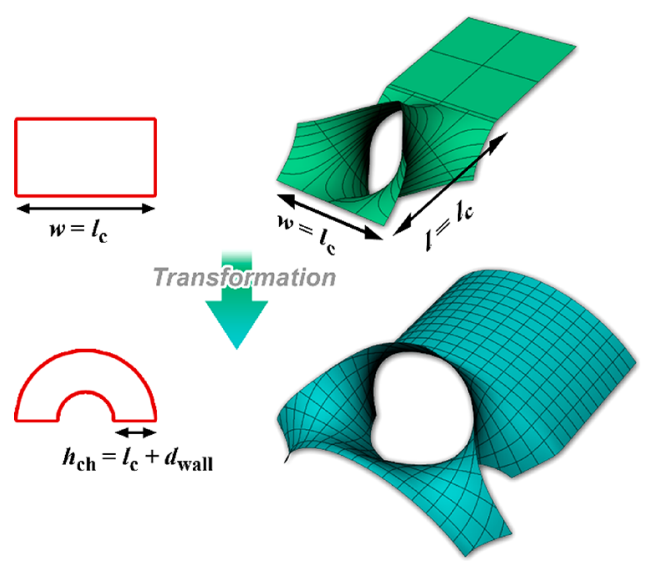

Figure 2. Transformation of the basic FGU into the desired shape. Based on the rectangular basic FGU shape the geometric surface is adapted to the desired shape by transforming B-Spline surface controlling points. The listed geometric variables represent the design parameters, which could be varied accordingly (compare also Table 1). Illustration adapted with permission from Hansjosten et $\mathrm{al.}^{22}$. Copyright 2018 Elsevier.

a braided manner from the inner to the outer surface of a cylinder and renewing the boundary layer is also beneficial to mass transfer. However, due to the two phases, additional restrictions apply to the choice of the parameters. Especially, two additional aims were considered as important:

- a uniform thin film preferably without the formation of rivulets

- equal distribution of the flow

In the original design for heat exchangers, the FGU is extended by planes of a certain length to guarantee a defined contact time of the resulting partial flows with the wall. In order to meet the above requirements for the absorption process, a convective mass transport within the film was targeted while the film itself should be held by capillary forces along the FGE. By design, this was addressed by removing the planar part of the FGE (see Figure 3). Furthermore, the characteristic length of the FGU was drastically reduced from a couple of millimeters to the range of capillary forces (submillimeter regime).

The model was fully parametrized. Therefore, in principle every geometric parameter (height of channel $h_{\mathrm{ch}}$, width $w$, and channel length $l$ ) could be varied easily, only restricted by the building restrictions of the SLM process itself. However, to achieve geometric similarity of the basic FGU for the first principal investigations a characteristic length $l_{c}$ was defined. Derived therefrom every geometric parameter was altered correspondingly. The design parameters defined according to the above-mentioned considerations are listed in Table 1 for 


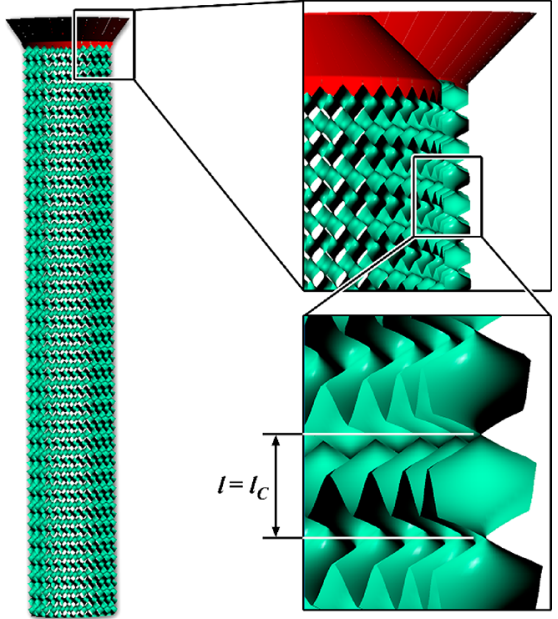

Figure 3. Detailed view of the design model of the adapted FGE for absorption processes. As shown in the detailed view the flow distributor is seamlessly connected to the FGE structure.

Table 1. Geometric Design Parameters of the Used FGE

\begin{tabular}{llll}
\multicolumn{1}{c}{ parameter } & FGE type 1 & FGE type 2 & FGE type 3 \\
characteristic length $l_{\mathrm{c}}(\mathrm{mm})$ & 0.5 & 0.75 & 1.0 \\
wall thickness $d_{\mathrm{w}}(\mu \mathrm{m})$ & 180 & 180 & 180 \\
$d_{\mathrm{w}}$ to $l_{\mathrm{c}}$ ratio & 0.36 & 0.24 & 0.18 \\
diameter of FGE $d_{\mathrm{FGE}}(\mathrm{mm})$ & 10 & 10 & 10 \\
channel height $h_{\mathrm{ch}}$ & $l_{\mathrm{c}}+d_{\mathrm{w}}$ & $l_{\mathrm{c}}+d_{\mathrm{w}}$ & $l_{\mathrm{c}}+d_{\mathrm{w}}$ \\
channel with $w$ & $l_{\mathrm{c}}$ & $l_{\mathrm{c}}$ & $l_{\mathrm{c}}$ \\
channel length $l$ & $l_{\mathrm{c}}$ & $l_{\mathrm{c}}$ & $l_{\mathrm{c}}$ \\
height of complete FGE $h(\mathrm{~mm})$ & 50 & 50 & 50
\end{tabular}

the three types of FGEs with different characteristic lengths $l_{\mathrm{c}}$ of $0.5,0.75$, and $1.0 \mathrm{~mm}$. Since the wall thickness is constant for all the elements, they are not strictly geometrically equal and thus the portion of wetted surfaces in relation to the whole element grows with $l_{\text {c }}$.

To dose and distribute the fluid over the circumference of the cylindrical FGE, a funnel-shaped inlet (see Figure 3, section: $4.5 \mathrm{~mm} \mathrm{~mm}$ at the most upper part; height: $2.25 \mathrm{~mm}$ ) was printed directly on top of the FGE structure. This seamless connection by the design and manufacturing method of two different functional elements shows an advantage of AM. This funnel can serve as a reservoir of liquid. The liquid level in the funnel reservoir is controlled by the hydrostatic pressure and the pressure loss imposed by the orifices. This fully parametrized funnel structure could also be altered according to the necessities of the device and its application.

In Figure 4 the principal design idea is illustrated. When trickling along the FGE, the fluid is guided through small orifices from the inner to the outer surface and vice versa (blue arrows in Figure 4). Equation 1 shows the relationship between the characteristic time for diffusion of gas into a liquid film, $\tau$, as a function of the diffusion length, $l_{\mathrm{D}}$, and the diffusion coefficient, $D$.

$$
\tau=\frac{l_{\mathrm{D}}{ }^{2}}{D}
$$

By utilizing both the outer and inner surfaces of the FGE for providing a thin film, the characteristic time is theoretically reduced by a factor of 4 as a result of the halving of the diffusion length $l_{\mathrm{D}}$ compared to a one-sided falling film. ${ }^{25}$

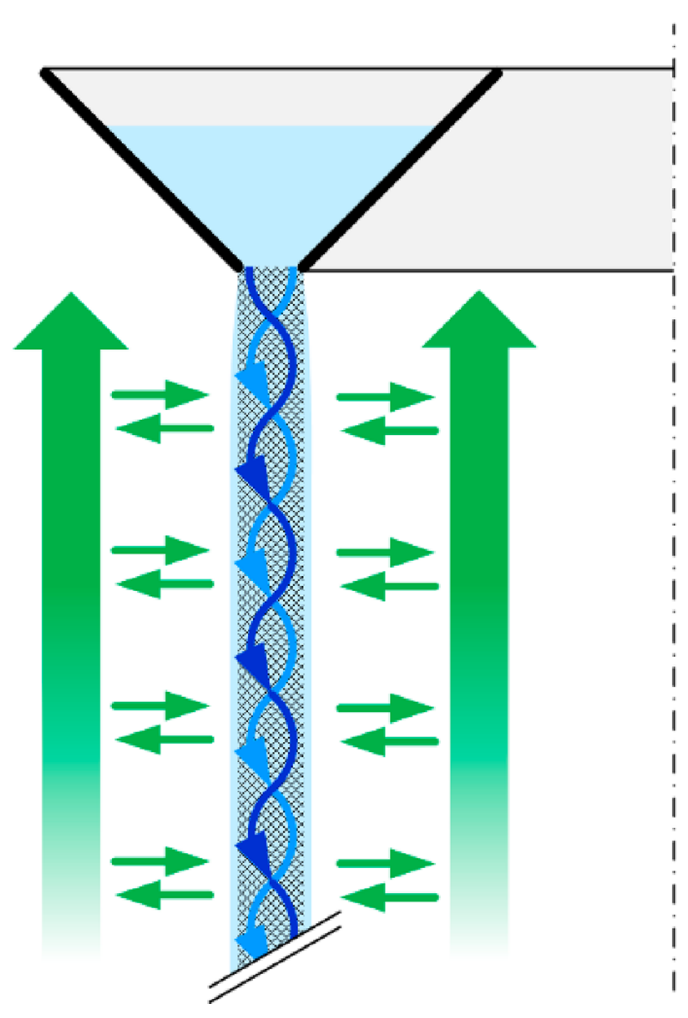

Figure 4. Schematic illustration of the principal idea of the FGE for absorption processes. The liquid (blue color) is distributed via a funnel structure. Through the microstructuring the flow is guided and mixed between the inner and outer sides of the FGE. The gas (green arrows) is flowing counter currently on the inner and outer surface of the FGE.

\section{EXPERIMENTAL SECTION}

3.1. Manufacturing of the FGE. The fluid guiding elements (FGEs) were printed using a ReaLizer SLM125 (Germany) selective laser melting machine. As material 316L stainless steel powder with a particle size of 5-30 $\mu \mathrm{m}$ was used. Layer height was defined as $50 \mu \mathrm{m}$. The specific printing time of one FGE was in the range of a couple of minutes per element, if the building space was fully used. This value underlines the production-ready design of the elements.

3.2. Surface Characterization. Scanning electron microscopy (SEM) was performed using a JSM-6300 with a $10 \mathrm{kV}$ beam (JEOL GmbH, Germany). To characterize the forced wetting of the FGE, the dry samples were weighed, completely dipped in deionized water, removed, and allowed to drain for $30 \mathrm{~s}$ before the weight gain extended by the adherent water film was measured.

3.3. Flooding Point. The FGEs were first tested visually on a perforated plate using water. Using a $1 / 16$ in. steel capillary a defined flow was put in the cone. The water flow rate was increased stepwise until the cone was completely filled and overflowed, which indicated that the FGE had reached the flooding point. When the annular gap of the cone was completely covered for the first time, this value was defined as minimum load $\dot{m}_{\mathrm{ml}}$.

3.4. Absorption of $\mathrm{CO}_{2}$ in $\mathrm{NaOH}$ Solution. The absorption of $\mathrm{CO}_{2}$ into an aqueous solution of $\mathrm{NaOH}$ has been chosen as a model system to characterize the mass transfer with the FGE. This is a well-established method for probing the mass transfer performance of gas-liquid 
contacting devices relying on a fast chemical reaction of the absorbed gas in the liquid absorbent. ${ }^{26-28}$ The overall reaction is given in eq 5 . The step can be divided in the partial reactions $2-4)$. Reaction 4 is almost instantaneous. ${ }^{27}$ For $\mathrm{pH}$ values above 11 reaction 4 of hydrogen carbonate to carbonate is nearly complete. ${ }^{29}$

$$
\begin{aligned}
& \mathrm{CO}_{2}(\mathrm{~g}) \rightleftharpoons \mathrm{CO}_{2}(\mathrm{aq}) \\
& \mathrm{CO}_{2}(\mathrm{aq})+\mathrm{OH}^{-}(\mathrm{aq}) \rightleftharpoons \mathrm{HCO}_{3}^{-}(\mathrm{aq}) \\
& \mathrm{HCO}_{3}^{-}(\mathrm{aq})+\mathrm{OH}^{-}(\mathrm{aq}) \rightleftharpoons \mathrm{CO}_{3}^{2-}(\mathrm{aq})+\mathrm{H}_{2} \mathrm{O} \\
& \mathrm{CO}_{2}(\mathrm{~g})+2 \mathrm{OH}^{-}(\mathrm{aq}) \rightleftharpoons \mathrm{CO}_{3}^{2-}(\mathrm{aq})+\mathrm{H}_{2} \mathrm{O}
\end{aligned}
$$

In Figure 5 a schematic of the test apparatus is shown. The absorber consists of an outer stainless-steel tube $(18 \times 1 \mathrm{~mm})$

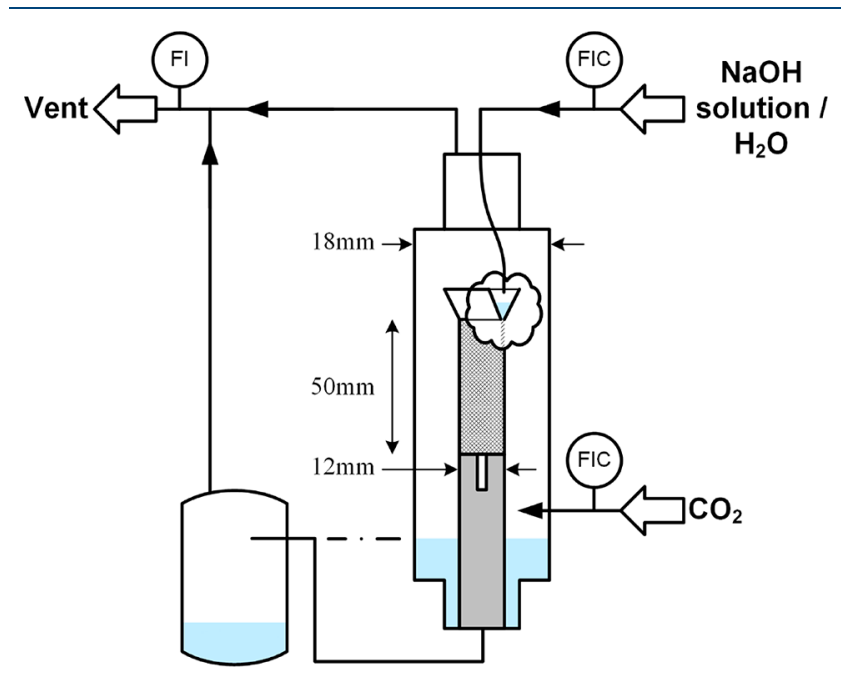

Figure 5. Schematic of the setup for the absorption measurements of $\mathrm{CO}_{2}$ in a liquid absorbent. All diameters discribe the outer tube diameter.

and a shorter inner $12 \times 1 \mathrm{~mm}$ slotted steel tube where the FGE was clamped. Via a $1 / 16$ in. capillary the flow was dosed into the funnel reservoir. Following the communicating vessel principle, the liquid level in the apparatus was adjusted to reduce the wetted surface in the lower liquid collecting tank.

The sodium hydroxide solution was dosed into the funnel reservoir using a Coriolis mass flow controller (mini CORIFLOW, Bronkhorst High-Tech B.V., Netherlands) fed from a pressurized $\left(\mathrm{N}_{2}\right)$ buffer tank. The $\mathrm{CO}_{2}$ flow was dosed using a mass flow controller (EL-FLOW, Bronkhorst High-Tech B.V., Netherlands). The flow rate was chosen such that $\mathrm{CO}_{2}$ was always present in excess. The gas flow through the vent was measured by a flowmeter (Definer 220, DryCal, U.S.A.). The experimental parameters are given in Table 2. The degree of conversion of $\mathrm{NaOH}$ with $\mathrm{CO}_{2}$ to sodium carbonate, representing the amount of absorbed $\mathrm{CO}_{2}$, was calculated

Table 2. Experimental Conditions

\begin{tabular}{ll}
\multicolumn{1}{c}{ parameter } & \multicolumn{1}{c}{ range } \\
$\mathrm{CO}_{2}$ flow rate $\dot{V}_{\mathrm{CO}_{2} \text {,in }}\left(\mathrm{mL}_{\mathrm{N}} \mathrm{min}^{-1}\right)$ & 400 \\
$\mathrm{NaOH}$ concentration $(\mathrm{M})$ & 2 \\
$\mathrm{NaOH}$ solution flow rate $\left(\mathrm{g} \mathrm{h}^{-1}\right)$ & $200,400,600,800,1000$ \\
temperature $(\mathrm{K})$ & 297
\end{tabular}

according to eq 6 taking also the displacement of gas by the dosed liquid into account:

$$
\begin{aligned}
X_{\mathrm{CO}_{2}-\mathrm{NaOH}(\mathrm{aq})} & =\frac{\dot{n}_{\mathrm{CO}_{2}, \text { in }}-\dot{n}_{\mathrm{CO}_{2}, \text { out }}}{\dot{n}_{\mathrm{CO}_{2}, \text { abs, } \max }} \\
& =\frac{\dot{V}_{\mathrm{CO}_{2}, \text { in }}-\left(\dot{V}_{\mathrm{CO}_{2}, \text { out }}-\dot{V}_{\text {liquid,in }}\right)}{\dot{V}_{\mathrm{CO}_{2}, \text { abs } \text { max }}}
\end{aligned}
$$

where $\dot{n}_{\mathrm{CO}_{2} \text {,abs,max }}$ and $\dot{V}_{\text {abs,max }}$ denotes the maximum molar flow and volume flow (assuming ideal gas behavior) of $\mathrm{CO}_{2}$ which, theoretically, can be absorbed assuming full conversion of the $\mathrm{NaOH}$ feed to sodium carbonate according to eq 5. Due to measurement by the flowmeter the accuracy was high (typically $<1 \%$ error).

3.5. Absorption of $\mathrm{CO}_{2}$ in $\mathrm{H}_{2} \mathrm{O}$. In microstructured devices with fast chemical reactions like eq 3 , it can be difficult to quantify the impact of the initial $\mathrm{CO}_{2}$ absorption step. ${ }^{23}$ To allow us to study this step, we measured the $\mathrm{CO}_{2}$ absorption coefficient $k_{1}$ in pure water using the same apparatus. After a run-in time of at least $15 \mathrm{~min}$ the lower sample bottle was replaced by a weighted sample bottle containing $2 \mathrm{~mL}$ of $2 \mathrm{M}$ $\mathrm{NaOH}$ solution. Thereby the absorbed $\mathrm{CO}_{2}$ was converted according to eq 5 into bicarbonate to avoid degassing of the $\mathrm{CO}_{2}$. Then samples of around $50 \mathrm{~mL}$ were collected. To determine the remaining hydroxide and deduce the $\mathrm{CO}_{2}$ concentration, the solution was titrated with hydrochloric acid after precipitation of the carbonate with $\mathrm{BaCl}_{2}$ according to eq 7 to determine the remaining hydroxide concentration by eq $8 .{ }^{30}$ The procedure was verified by blank titrations. The accuracy was not as high as with the flowmeter with a standard deviation typically lower than $4 \%$ due to the multiple steps. A measurement by the flowmeter was not feasible due to the lower amount of absorbed gas.

$$
\begin{gathered}
\mathrm{Ba}^{2+}+\mathrm{CO}_{3}^{2-}(\mathrm{aq}) \rightarrow \mathrm{BaCO}_{3}(\mathrm{~s}) \downarrow \\
c_{\mathrm{CO}_{2}, \text { out }}=\frac{0.004 \mathrm{~mol}-V_{\mathrm{HCl}} \cdot c_{\mathrm{HCl}}}{2 \cdot V_{\text {Sample }}}
\end{gathered}
$$

The absorption efficiency was calculated similar to the absorption in $\mathrm{NaOH}$ solution according to eq 9

$$
X_{\mathrm{CO}_{2}-\mathrm{NaOH}(\mathrm{aq})}=\frac{\dot{n}_{\mathrm{CO}_{2} \text {,in }}-\dot{n}_{\mathrm{CO}_{2}, \text { out }}}{\dot{n}_{\mathrm{CO}_{2}, \mathrm{Abs}, \max }}=\frac{c_{\mathrm{CO}_{2}, \text { out }}-c_{\mathrm{CO}_{2} \text {,in }}}{c_{\mathrm{sat}}^{*}-c_{\mathrm{CO}_{2}, \text { in }}}
$$

where $c_{\mathrm{CO}_{2} \text {,in }}=0 \mathrm{~mol} \mathrm{~L}{ }^{-1}$ and $c_{\text {sat }}^{*}$ was calculated according to Sander. ${ }^{31}$

3.6. Chemicals. Ultrapure distilled water was obtained using a purification system (Milli-Q-Water, Merck, Germany). Sodium hydroxide (extra pure, Kraft, Germany), $\mathrm{HCl}$ (p.A., Merck, Germany), and barium chloride (p.A., VWR, Germany) were used as purchased. $\mathrm{CO}_{2}$ was used in grade N4.5 (Air Liquide).

\section{RESULTS AND DISCUSSION}

4.1. Surface Properties. In Figure 6, SEM micrographs of the elements with the different characteristic lengths $l_{c}$ are shown. The wall thickness is approximately $180 \mu \mathrm{m}$ for all three samples. Even for the smallest value of $l_{\mathcal{c}}$ the desired shape was obtained as designed. This underpins the suitability of the SLM technology to print precisely fine details in the micrometer range. However, the surface is covered with partly 

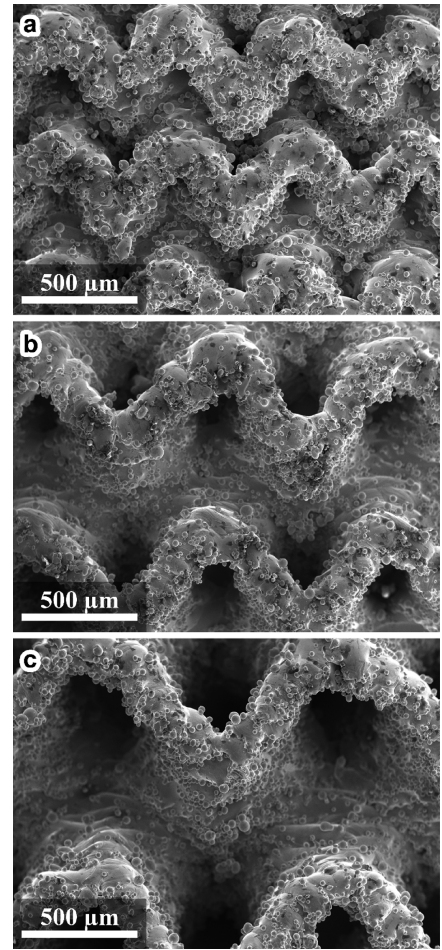

Figure 6. SEM pictures of FGE with different characteristic lengths $d_{c}$. (a) $0.50 \mathrm{~mm}$, (b) $0.75 \mathrm{~mm}$, and (c) $1.00 \mathrm{~mm}$.

melted particle residues in the size range of 10 to $50 \mu \mathrm{m}$. Especially for the FGE with the smallest characteristic length investigated $(0.5 \mathrm{~mm})$, these residues are in the same size regime as the fluid passages of the FGE which brings about a risk of blocking the pores. This clearly poses a challenge in printing fine structures. Especially in closed channels, the removal of the powder is difficult. Due to the open structure of the elements the removal of loose powder is rather simple for the presented FGE. The residues moreover enlarge the specific surface area of the FGE, which on one hand increases the pressure drop but on the other hand also promotes film formation and is therefore potentially beneficial when it comes to coatings for application as supports in, e.g., heterogeneous catalysis.

4.2. Wetting. The wetting behavior of the elements is especially important for a uniform distribution of the fluid and for suppression of rivulet flows, respectively. ${ }^{23}$ In Table 3 the amount of water on the surface of the FGEs of different characteristic lengths $l_{\mathrm{c}}$ after complete immersion in water and allowing to drain (30 s) is given.

\section{Table 3. Results of the Wetting Experiments}

\begin{tabular}{cccc} 
FGE type & $l_{\mathrm{c}}(\mathrm{mm})$ & $\Delta m(\mathrm{~g})$ & $d_{\text {Film }}(\mathrm{mm})$ with cylinder surface \\
1 & 0.50 & 0.42 & 0.14 \\
2 & 0.75 & 0.64 & 0.21 \\
3 & 1.00 & 0.79 & 0.26 \\
\hline
\end{tabular}

The amount of water clearly scales with the characteristic length. By dividing the volume of water through the surface of a straight cylinder the theoretical static film thickness was calculated for each sample. These values are in the same order of magnitude as the characteristic length $l_{\mathrm{c}} / 3$.
4.3. Flooding Point. As described in Section 3.2, the flooding points $\dot{m}_{\mathrm{fp}}$, of the different FGEs were determined. The flooding point characterizes the point when the liquid level was so high that the liquid was flowing over the edge of the funnel. The results of the three different types investigated are shown in Table 4. As expected, there is a strong relation

Table 4. Results of Flooding Tests of Different FGE Types

$\begin{array}{ccc}\begin{array}{c}\text { FGE } \\ \text { type }\end{array} & \begin{array}{c}\text { average } \\ \left(\mathrm{g} \mathrm{h}^{-1}\right)\end{array} & \begin{array}{c}\text { average flooding point } \dot{m}_{\mathrm{fp}} \\ \left(\mathrm{g} \mathrm{h}^{-1}\right)\end{array} \\ 1 & <10 & 16 \\ 2 & 3.5 \times 10^{2} & 1.1 \times 10^{3} \\ 3 & >2.0 \times 10^{3} & >2.0 \times 10^{3}\end{array}$

between $l_{c}$ and the maximum load. The FGE type 1 with a characteristic length of $0.5 \mathrm{~mm}$ has a flow rate almost 70 times smaller than that of the type 2 elements (see Table 4 ). This is more than expected from a simple laminar approach based on the solution for the Hagen-Poiseuille eq 10 assuming circular orifices of the radius and length proportional to the characteristic length corrected by the wall thickness $d_{w}$, material properties (density $\rho$ and viscosity $\eta$ ), and constant pressure difference $\Delta p$. Calculating the ratio for the two characteristic lengths results in eq 11 where the flow is proportional to $l_{\mathrm{c}}^{3}$.

$$
\begin{aligned}
& \dot{m}_{\mathrm{fp}} \sim \frac{\pi \cdot r^{4}}{8 \cdot \eta \cdot \rho \cdot L} \cdot \Delta p \\
& \frac{\dot{m}_{\mathrm{fp}, \text { type } 1}}{\dot{m}_{\mathrm{fp}, \text { type } 2}} \approx\left(\frac{l_{\mathrm{c} \text {,type } 1}-d_{\mathrm{w}}}{l_{\mathrm{c}, \text { type } 2}-d_{\mathrm{w}}}\right)^{3}=\frac{1}{5.6}
\end{aligned}
$$

Type 3 elements could not be flooded with the maximal available load of $2000 \mathrm{~g} \mathrm{~h}^{-1}$. Not only the flooding point characterizes the operating parameters. Also a certain liquid load is needed to generate a uniform distribution over the whole circumference of the FGE. The determined values are also given in Table 4. If the flow rate is too low (drain from the liquid reservoir is larger than the supply), a maldistribution along the FGE as illustrated in Figure $7 \mathrm{~b}$ occurs. Is has to be

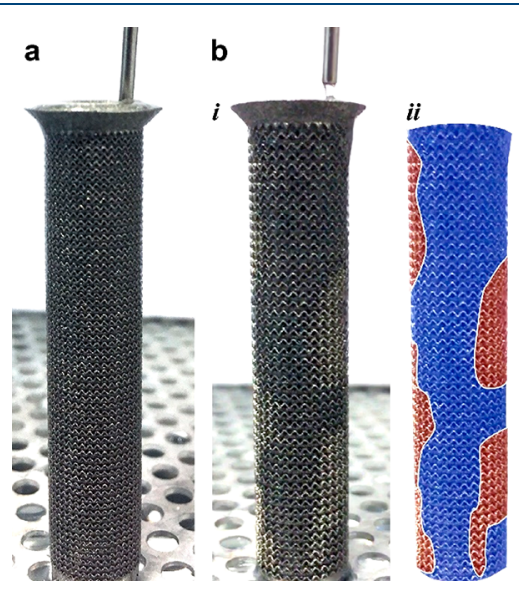

Figure 7. Exemplary pictures of the flood point investigations. (a) For flooded FGE type 2 the liquid level is higher than the funnel, resulting in over flowing, (b, i) maldistribution in FGE type 3 through a low liquid level in the flow distributor, and (b, ii) the dry (red) and wetted areas (blue) are highlighted. 
mentioned that the average minimum load $\dot{m}_{\mathrm{ml}}$ of FGE type 3 is near $2000 \mathrm{~g} / \mathrm{h}$. Owing to the upper limit of the mass flow controller of $2000 \mathrm{~g} / \mathrm{h}$ no exact value can be given.

The flooding point, in addition, also depends on the height of the funnel. However, due to the fact that the fluid passages from the funnel reservoir to the FGE are of the same geometry as the FGE itself, the results are a strong indication that the operating point in terms of flow range is suitable for the whole FGE structure.

4.4. $\mathrm{CO}_{2}$ Absorption into $\mathrm{NaOH}$ Solution Using Fluid Guiding Elements. A $2 \mathrm{M}$ solution of $\mathrm{NaOH}$ was dosed as described in Section $3.4 \mathrm{CO}_{2}$ was dosed counter-currently. From the mass balance of the $\mathrm{CO}_{2}$ stream the conversion of $\mathrm{NaOH}$ and therefore the absorbed amount of $\mathrm{CO}_{2}$ were determined according to eq 6 . The results of the absorption test are depicted in Figure 8. Due to the flooding point results

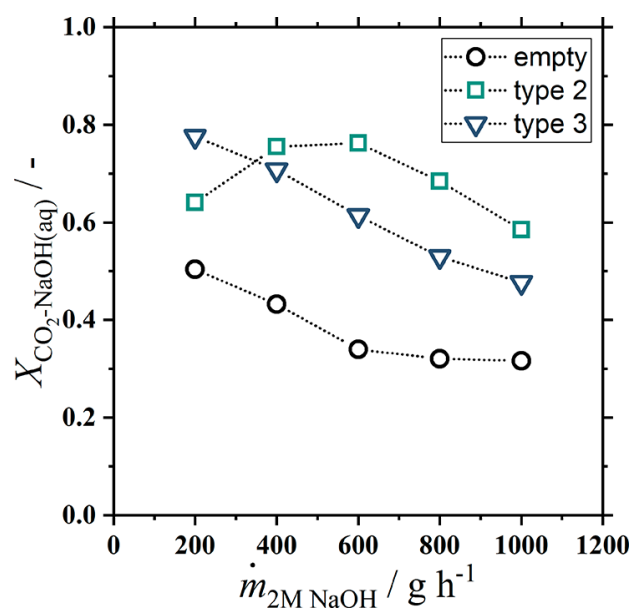

Figure 8. Absorption efficiency for two types of FGEs as a function of $\mathrm{NaOH}$ stream in comparison to blind measurement.

described above, the fluid guiding element type 1 was not further examined. From the reference experiment (no FGE installed in the absorption test setup) absorption of $\mathrm{CO}_{2}$ was determined. First, the results account for the amount of wetted surface in the apparatus, and second, through the small capillary also small droplets were generated. Therefore, this result can be regarded as a comparison to a conventional spray absorption column. However, a clear increase in $X_{\mathrm{CO} 2-\mathrm{NaOH}(\mathrm{aq})}$ can be observed with an FGE installed. The type 3 FGE, being built up of elements with larger characteristic length and, thus, coarser elements, shows a significant increase with respect to the blank test. With the smallest liquid flow rate investigated $\left(200 \mathrm{~g} \mathrm{~h}^{-1}\right)$, the type 3 FGE reaches nearly $80 \%$ absorption of $\mathrm{CO}_{2}$ in $\mathrm{NaOH}$, exceeding the blank experiment by $30 \%$. With increasing liquid load, the type 2 FGE exceeds this gain in the degree of absorption compared to the blank experiment (up to $+40 \%$ at $600 \mathrm{~g} \mathrm{~h}^{-1}$ ) as the smaller characteristic length of the type 2 FGE provides a larger surface area and improved mixing of the fluid film. At higher fluid flow rates the absorption of type 2 is much more efficient than with the element type 3 of larger characteristic length. However, for type 2 a maximum in $X_{\mathrm{CO} 2-\mathrm{NaOH}(\mathrm{aq})}$ seems to be at 400 , and $600 \mathrm{~g} \mathrm{~h}^{-1}$ was observed with an absorption efficiency at $200 \mathrm{~g} \mathrm{~h}^{-1}$ of approximately $60 \%$ being on the one hand still larger than the blank reference but smaller than the one obtained for the type 3 FGE. This behavior could be attributed to a maldistribution caused by the low flow rate. As already mentioned, due to incomplete filling of the circumference of the funnel a maldistribution is probable. As mentioned in Section 4.2, type 3 is far away from the minimum load for complete wetting, so a complete description of the behavior is at least difficult. If a constant wetted area as well as a constant average flow velocity over all the wetted area is assumed then with increase of volume flow an increase of film thickness would be expected, resulting in a smaller mass transfer and thus in a decrease in efficiency. However, that trend should reverse when the wetted area increases. So, the expectation would be that with further increase in flow at some point dry spots will be wetted, increasing simultaneously area and residence time and thus absorption efficiency.

In fact the observation using FGE type 2 supports this expectation, since a noticeable increase from the flow below the minimum load to the point where complete wetting can be safely assumed.

That the absolute absorption efficiency of type 3 at partially wetted condition is higher than that for type 2 at the same load can be understood when considering that the area of type 3 elements is higher due to the thickness of the layer. Thus, film thickness and residence time of the liquid is higher at that point in absolute values.

4.5. $\mathrm{CO}_{2}$ Absorption into Water Using Fluid Guiding Elements. In order to quantify the absorption process and to determine the $k_{1}$ value, measurements of $\mathrm{CO}_{2}$ absorption in water were conducted with the type 2 FGE. We had chosen type 2 due to the previous results. The results are shown in Figure 9 and Figure 10. Qualitatively, $\mathrm{CO}_{2}$ absorption in water

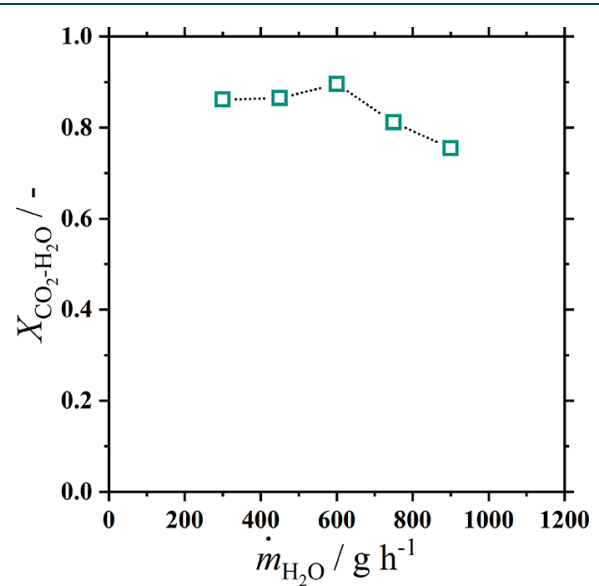

Figure 9. Absorption efficiency of $\mathrm{CO}_{2}$ in water versus water flow rate with the FGE type 2.

follows the same trend in terms of degree of absorption vs liquid flow as the absorption in sodium hydroxide solution. However, the effects are less pronounced, which can be attributed to the lower amount of material transferred due to the missing reaction, which keeps the gradient in the film high. The results are quite near a complete saturation. Based on the values obtained, the $k_{1}$ value can be determined by eq 12 following Dankwerts ${ }^{26}$ and Zhang et al., ${ }^{32}$

$$
k_{1}=-\frac{\dot{V}_{1}}{A} \ln \left(\frac{c_{\mathrm{sat}}^{*}-c_{\mathrm{CO}_{2}, \mathrm{out}}}{c_{\mathrm{sat}}^{*}}\right)
$$

where $\dot{V}_{1}$ represents the water flow rate, $A$ the geometric contacting area of the cylindrical surface, corresponding to the 


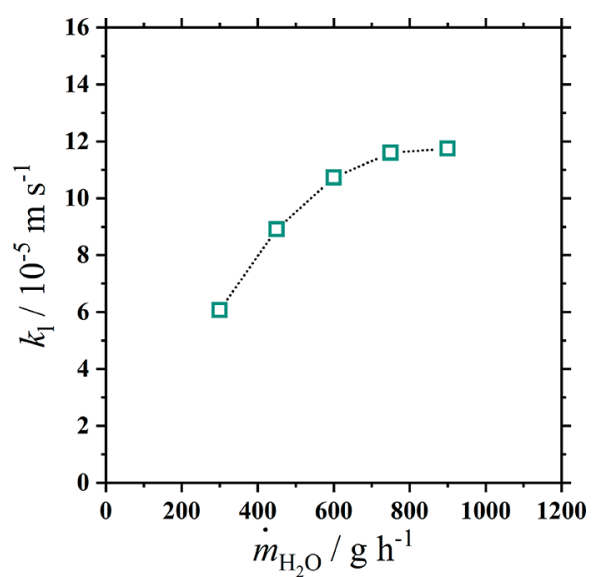

Figure 10. Influence of water flow rate on mass transfer coefficient $k_{1}$ of FGE type 2.

calculations for microstructured devices in literature, ${ }^{32}$ and $c_{\text {sat }}^{*}$ and $c_{\mathrm{CO}_{2} \text {,out }}$ the saturation concentration calculated ${ }^{31}$ and the measured output concentration, respectively. The results of the calculation are depicted in Figure 10. The $k_{1}$ value increases with the liquid flow rate, probably due to the decreasing residence time of the liquid, which increases the gradient at the gas-liquid interface. This was also found by Zhang et al. ${ }^{32}$ Depending on the fluid flow rate applied, a mass transfer coefficient $k_{1}$ in the range of $0.61 \times 10^{-4}$ to $1.2 \times 10^{-4} \mathrm{~m} \mathrm{~s}^{-1}$ was achieved. These values are in the range of previously reported $k_{1}$ values for microstructured falling film devices (compare also Table 5). An increase of $k_{1}$ with increasing liquid flow rate was also described in Zhang et al. ${ }^{32}$

Table 5. Comparison with Different Reported $k_{1}$ Values in the Literature

\begin{tabular}{llc}
\multicolumn{1}{c}{ reference } & \multicolumn{1}{c}{ type of reactor } & $k_{1}\left(10^{-5} \mathrm{~m} \mathrm{~s}^{-1}\right)$ \\
Zhang et al. $^{32}$ & falling film microreactor & $5.83-13.4$ \\
${\text { Chen et } \mathrm{al}^{24}}$ & falling film microreactor with mixing & $3.59-5.38$ \\
this work & FGE & $6.1-11.9$ \\
\hline
\end{tabular}

\section{CONCLUSIONS}

The basic concept of 3D printed, thin wall fluid guiding elements was adapted to the requirements of absorption processes, namely, increasing gas-liquid interface and enforcing convective mixing of the liquid film in order to overcome mass transfer limitations.

From the results obtained, the following conclusions can be drawn:

- Using selective laser melting, fluid guiding elements of fine structured guiding elements with wall thickness of only $180 \mu \mathrm{m}$ can be manufactured.

- The characteristic length of guiding elements predetermines wetting behavior, surface area, and, thus, gas liquid mass transfer in the $\mathrm{CO}_{2}$ absorption

- In general, the FGE structures show enhanced gasliquid mass transfer in the $\mathrm{CO}_{2}$ absorption as compared to the blank reference.

- The absorption coefficient $k_{1}$ is in the same range as that reported for microstructured falling film devices.

- Following the design concept presented, the FGE can be further tailored to the needs of a given application- production time (and cost) are low. In addition, by varying individual parameters of the basic design concept, the behavior of the FGE in gas-liquid applications can be tailored freely.

\section{OUTLOOK}

In the fast-developing field of additive manufacturing of metallic structures with a very high degree of freedom in terms of geometry, some ideas have been shown which have the potential to surpass current limitations in the design and manufacturing of devices with regard to geometrical optimization of devices to the physics of a given application. In combination with simulation-guided design, further improvements are feasible. Further research on the characterization and developments are necessary to take advantage of the full potential of this technique and the approaches followed to bring it into application in science and technology. Just by the FGE design strategy described in this work, the possibilities for geometry variations are vast. For example, in a more sophisticated fluid distributor the full potential of the FGE could be expanded. If further aspects such as surface modifications are considered in addition, there is a huge field opened to enhance heat and mass transfer in multiphase processes.

\section{AUTHOR INFORMATION}

\section{Corresponding Authors}

*Fabian Grinschek. E-mail: fabian.grinschek@kit.edu.

*Roland Dittmeyer. E-mail: roland.dittmeyer@kit.edu.

ORCID $\odot$

Michael Klumpp: 0000-0002-2670-0887

Roland Dittmeyer: 0000-0002-3110-6989

\section{Author Contributions}

The manuscript was written through contributions of all authors. All authors have given approval to the final version of the manuscript.

\section{Notes}

The authors declare no competing financial interest.

\section{ABBREVIATIONS}

$\mathrm{AM}=$ additive manufacturing

FGE = fluid guiding element

$\mathrm{FGU}=$ fluid guiding unit

SEM = scanning electron microscopy

SLM = selective laser melting

\section{Symbols}

$$
\begin{aligned}
& A=\text { area }\left[\mathrm{cm}^{2}\right] \\
& c=\text { concentration }\left[\mathrm{mol} \mathrm{L}^{-1}\right] \\
& d=\text { length/diameter }[\mathrm{mm}] \\
& D=\text { diffusion coefficient }\left[\mathrm{m} \mathrm{s}^{-2}\right] \\
& H=\text { height }[\mathrm{mm}] \\
& k=\text { mass transfer coefficient }\left[\mathrm{m} \mathrm{s}^{-1}\right] \\
& L, l=\text { length }[\mathrm{mm}] \\
& m=\text { mass }[\mathrm{kg}] \\
& n=\text { amount of substance }[\mathrm{mol}] \\
& p=\text { pressure }[\mathrm{Pa}] \\
& r=\text { radius }[\mathrm{m}] \\
& V=\text { Volume }[\mathrm{L}] \\
& \dot{V}=\text { flow rate }\left[\mathrm{m}^{3} \mathrm{~s}^{-1}\right] \\
& w=\text { width }[\mathrm{mm}] \\
& X=\text { conversion }[-]
\end{aligned}
$$




\section{Greek symbols}

$\eta=$ dynamic viscosity $[\mathrm{mPa} \mathrm{s}]$

$\rho=$ density $\left[\mathrm{kg} \mathrm{cm}^{-3}\right]$

$\tau=$ characteristic time scale $[\mathrm{s}]$

\section{Indices}

abs $=$ absorption

$\mathrm{c}=$ characteristic

ch $=$ channel

$\mathrm{fp}=$ flooding point

$\mathrm{Geo}=$ geometric

in $=$ inlet

$1=$ length

$\mathrm{L}=$ liquid

$\max =$ maximum

$\mathrm{ml}=$ minimun load

out $=$ outlet

sat $=$ saturation

wall $=$ wall

\section{REFERENCES}

(1) Hornung, C. H. The Art of Manufacturing Molecules. Science 2018, 359, 273-274.

(2) Brandner, J. J.; Anurjew, E.; Bohn, L.; Hansjosten, E.; Henning, T.; Schygulla, U.; Wenka, A.; Schubert, K. Concepts and Realization of Microstructure Heat Exchangers for Enhanced Heat Transfer. Exp. Therm. Fluid Sci. 2006, 30, 801-809.

(3) Wang, G.; Gu, Y.; Zhao, L.; Xuan, J.; Zeng, G.; Tang, Z.; Sun, Y. Experimental and Numerical Investigation of Fractal-Tree-Like Heat Exchanger Manufactured by 3D Printing. Chem. Eng. Sci. 2019, 195, 250-261.

(4) Haertel, J. H.K.; Nellis, G. F. A Fully Developed Flow Thermofluid Model for Topology Optimization of 3D-Printed AirCooled Heat Exchangers. Appl. Therm. Eng. 2017, 119, 10-24.

(5) Zeng, S.; Lee, P. S. Topology Optimization of Liquid-Cooled Microchannel Heat Sinks: An Experimental and Numerical Study. Int. J. Heat Mass Transfer 2019, 142, 118401.

(6) Hurt, C.; Brandt, M.; Priya, S. S.; Bhatelia, T.; Patel, J.; Selvakannan, P.; Bhargava, S. Combining Additive Manufacturing and Catalysis: A Review. Catal. Sci. Technol. 2017, 7, 3421-3439.

(7) Lämmermann, M.; Horak, G.; Schwieger, W.; Freund, H. Periodic Open Cellular Structures (POCS) for Intensification of Multiphase Reactors: Liquid Holdup and Two-Phase Pressure Drop. Chem. Eng. Process. 2018, 126, 178-189.

(8) Lämmermann, M.; Schwieger, W.; Freund, H. Experimental Investigation of Gas-Liquid Distribution in Periodic Open Cellular Structures as Potential Catalyst Supports. Catal. Today 2016, 273, $161-171$.

(9) Bianchi, E.; Schwieger, W.; Freund, H. Assessment of Periodic Open Cellular Structures for Enhanced Heat Conduction in Catalytic Fixed-Bed Reactors. Adv. Eng. Mater. 2016, 18, 608-614.

(10) Burns, N.; Burns, M.; Travis, D.; Geekie, L.; Rennie, A. E. W. Designing Advanced Filtration Media Through Metal Additive Manufacturing. Chem. Eng. Technol. 2016, 39, 535-542.

(11) Kalsoom, U.; Nesterenko, P. N.; Paull, B. Current and Future Impact of 3D Printing on the Separation Sciences. TrAC, Trends Anal. Chem. 2018, 105, 492-502.

(12) Bolton, S.; Kasturi, A.; Palko, S.; Lai, C.; Love, L.; Parks, J.; Xin, S.; Tsouris, C. 3D Printed Structures for Optimized Carbon Capture Technology in Packed Bed Columns. Sep. Sci. Technol. (Philadelphia, PA, U. S.) 2019, 54, 2047-2058.

(13) Neukäufer, J.; Hanusch, F.; Kutscherauer, M.; Rehfeldt, S.; Klein, H.; Grützner, T. Methodology for the Development of Additively Manufactured Packings in Thermal Separation Technology. Chem. Eng. Technol. 2019, 42, 1970.

(14) Mardani, S.; Ojala, L. S.; Uusi-Kyyny, P.; Alopaeus, V. Development of a Unique Modular Distillation Column Using 3D Printing. Chem. Eng. Process. 2016, 109, 136-148.
(15) Fee, C.; Nawada, S.; Dimartino, S. 3D Printed Porous Media Columns with Fine Control of Column Packing Morphology. J. Chromatogr. A 2014, 1333, 18-24.

(16) Hornung, C. H.; Nguyen, X.; Carafa, A.; Gardiner, J.; Urban, A.; Fraser, D.; Horne, M. D.; Gunasegaram, D. R.; Tsanaktsidis, J. Use of Catalytic Static Mixers for Continuous Flow Gas-Liquid and Transfer Hydrogenations in Organic Synthesis. Org. Process Res. Dev. 2017, 21, 1311-1319.

(17) Körner, C. Additive Manufacturing of Metallic Components by Selective Electron Beam Melting - A Review. Int. Mater. Rev. 2016, 61, 361-377.

(18) Guo, N.; Leu, M. C. Additive Manufacturing: Technology, Applications and Research Needs. Front. Mech. Eng. 2013, 8, 215243.

(19) Frazier, W. E. Metal Additive Manufacturing: A Review. J. Mater. Eng. Perform. 2014, 23, 1917-1928.

(20) Santos, E. C.; Shiomi, M.; Osakada, K.; Laoui, T. Rapid Manufacturing of Metal Components by Laser Forming. Int. J. Mach. Tool Manu. 2006, 46, 1459-1468.

(21) Travitzky, N.; Bonet, A.; Dermeik, B.; Fey, T.; Filbert-Demut, I.; Schlier, L.; Schlordt, T.; Greil, P. Additive Manufacturing of Ceramic-Based Materials. Adv. Eng. Mater. 2014, 16, 729-754.

(22) Hansjosten, E.; Wenka, A.; Hensel, A.; Benzinger, W.; Klumpp, M.; Dittmeyer, R. Custom-Designed 3D-Printed Metallic Fluid Guiding Elements for Enhanced Heat Transfer at Low Pressure Drop. Chem. Eng. Process. 2018, 130, 119-126.

(23) Hecht, K.; Kraut, M. Thermographic Investigations of a Microstructured Thin Film Reactor for Gas/Liquid Contacting. Ind. Eng. Chem. Res. 2010, 49, 10889-10896.

(24) Chen, S.; Zhang, T.; Lv, L.; Chen, Y.; Yang, Y.; Tang, S. Intensification of the Liquid Side Mass Transfer in Double-Side Falling Film Microchannels by Micro-Mixing Structures. Chem. Eng. Sci. 2019, 193, 264-275.

(25) Bottenus, D.; Caldwell, D.; Fischer, C.; Humble, P.; Powell, M.; Lucke, R.; TeGrotenhuis, W. Process Intensification of Distillation Using a Microwick Technology to Demonstrate Separation of Propane and Propylene. AIChE J. 2018, 64, 3690-3699.

(26) Danckwerts, P. V. Gas-liquid reactions; McGraw-Hill: New York, 1970.

(27) Sheng, M.; Xie, C.; Sun, B.; Luo, Y.; Zhang, L.; Chu, G.; Zou, H.; Chen, J.-F. Effective Mass Transfer Area Measurement Using a $\mathrm{CO} 2-\mathrm{NaOH}$ System: Impact of Different Sources of Kinetics Models and Physical Properties. Ind. Eng. Chem. Res. 2019, 58, 11082-11092.

(28) Ziegenbalg, D.; Löb, P.; Al-Rawashdeh, M.; Kralisch, D.; Hessel, V.; Schönfeld, F. Use of 'Smart Interfaces' to Improve the Liquid-Sided Mass Transport in a Falling Film Microreactor. Chem. Eng. Sci. 2010, 65, 3557-3566.

(29) Fleischer, C.; Becker, S.; Eigenberger, G. Detailed Modeling of the Chemisorption of $\mathrm{CO} 2$ into $\mathrm{NaOH}$ in a Bubble Column. Chem. Eng. Sci. 1996, 51, 1715-1724.

(30) Fleischer, C.; Becker, S.; Eigenberger, G. Transient Hydrodynamics, Mass-Transfer, and Reaction in Bubble-Columns: CO2 Absorption into $\mathrm{NaOH}$ Solutions. Chem. Eng. Res. Des. 1995, 73, 649-653.

(31) Sander, R. Compilation of Henry's Law Constants (Version 4.0) for Water as Solvent. Atmos. Chem. Phys. 2015, 15, 4399-4981.

(32) Zhang, H.; Chen, G.; Yue, J.; Yuan, Q. Hydrodynamics and Mass Transfer of Gas-Liquid Flow in a Falling Film Microreactor. AIChE J. 2009, 55, 1110-1120. 